\title{
Uranium-Contaminated Soils: Ultramicrotomy and Electron Beam Analysis*
}

\author{
by
}

E. C. Buck, N. L. Dietz, J. K. Bates, and J. C. Cunnane

Chemical Technology Division,

Argonne National Laboratory,

9700 South Cass Avenue, Argonne, IL 60439-4837
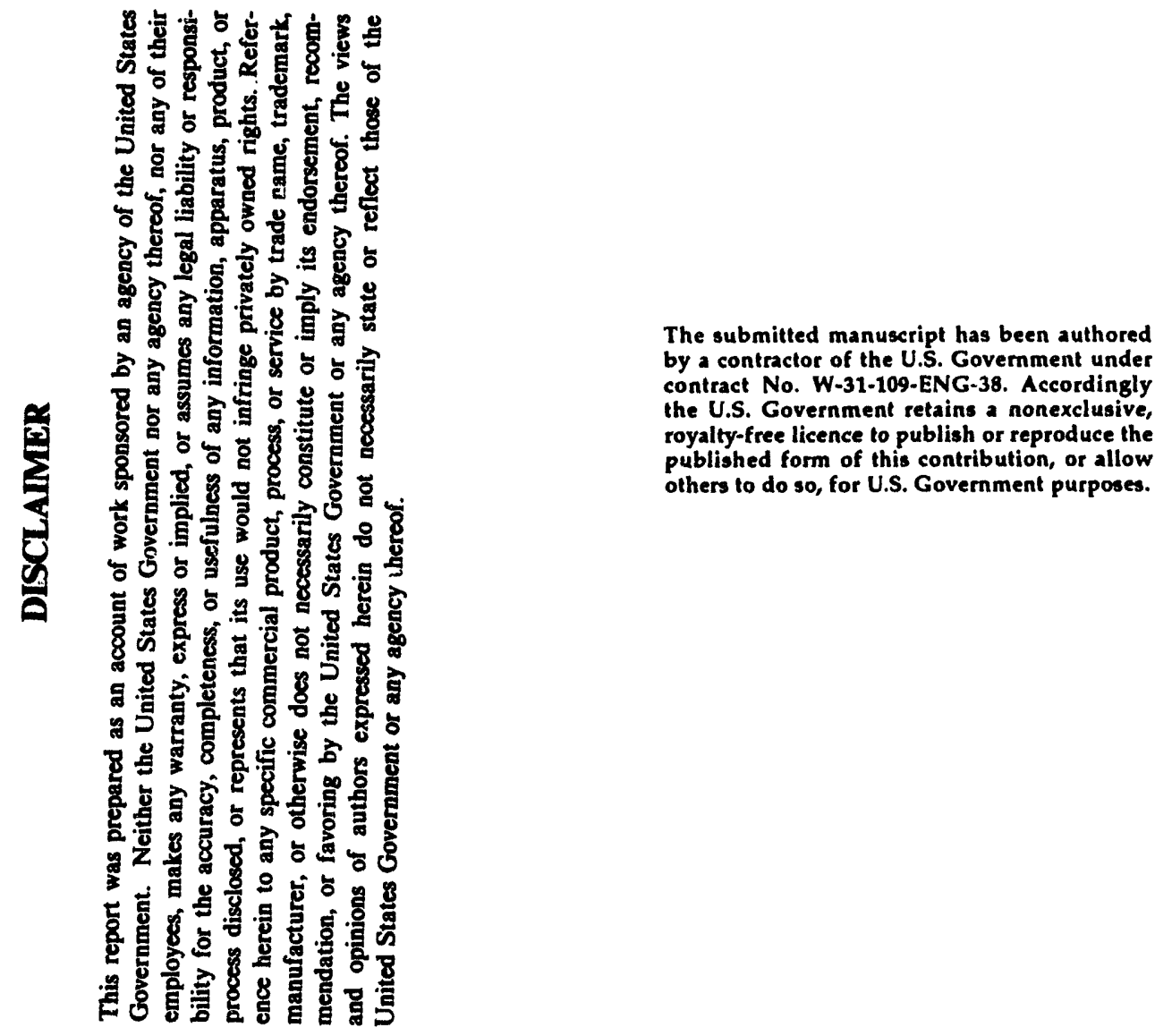

T CCEIVED

APR 181994

OSTI

*Work supported by the U.S. Department of Energy, Office of Technology Development, as part of the Uranium in Soils Integrated Demonstration Program, under contract W-31-109-ENG-38.

\section{MASTER}




\title{
Uranium-Contaminated Soils: Ultramicrotomy and Electron Beam Analysis
}

\author{
Edgar C. Buck*, Nancy L. Dietz, John K. Bates, and James C. Cunnane \\ Chemical Technology Division, Argonne National Laboratory, \\ 9700 South Cass Avenue, Argonne, IL 60439
}

Uranium contaminated soils from the Fernald Operation Site, Ohio, have been examined by a combination of optical microscopy, scanning electron microscopy with backscattered electron detection (SEM/BSE), and analytical electron microscopy (AEM). A method is described for preparing of transmission electron microscopy (TEM) thin sections by ultramicrotomy. By using these thin sections, SEM and TEM images can be compared directly. Uranium was found in iron oxides, silicates (soddyite), phosphates (autunites), and fluorite. Little uranium was associated with clays. The distribution of uranium phases was found to be inhomogeneous at the microscopic level.

\section{Introduction}

The Fernald Environmental Management Project (FEMP), formerly known as the Feed Materials Production Center, became contaminated with radioactive and toxic wastes generated during defense related uranium processing operations. The U.S. Department of Energy (DOE) suspended production there in 1986 and is now involved in remediation of the site (1). A remediation technology project begins with a characterization of the nature and distribution of the uranium contamination: then, once the characterization is complete, chemical and physical separation technologies are developed. To be effective both the characterization and separation aspects of the program require knowledge of the nature and distribution of uranium in the soil.

Uranium weathering. To characterize soil samples it is necessary to know how the 
uranium released during the processing operations at the site has begun to interact with the local environment. Such interactions, termed "weathering", will affect the transportability of uranium in the groundwater system. Uranium weathering transforms the primary uranium-bearing phases into secondary minerals or causes the liranium to be incorporated into other phases. At the uranium deposit at Koongarra, Australia, studies have been conducted to understand the behavior of uranium in the environment $(2,3)$. There, weathering of the rock resulted in uranium following the distribution patterns of iron oxide/oxyhydroxides.

Penetration of iron, uranium, and oxidizing ccnditions occurred preferentially along chlorite veins, where the rock structure may have been weak. Biotite (mica group) was also enriched with uranium during alteration, suggesting that uranium closely followed the weathering fronts. Solution extraction procedures confirmed the findings of electron microscopy investigations at Koongarra, demonstrating the value of microscopy in characterizing the distribution of uranium in the environment. Example of weathering of uraninite $\left(\mathrm{UO}_{2}\right)$ have also been described in studies related to the disposal of spent fuel from nuclear reactors. The sequence of secondary phase formation were remarkably similar in both laboratory tests (4) and natural settings (5); these results suggest that, weathering may occur at the Fernald site.

Source of uranium contamination in Fernald soils. At FEMP, the soil generally was contaminated by three sources: airborne uranium dust particles, aqueous uranium wastes, and sclid uranium product spills (1). An extensive sampling program has identified the areas of major contamination and current efforts are focused on further analysis of selected samples. In this investigation soil fractions taken from two different sampling positions (SP) have been analyzed. One fraction analyzed, from SP4 (Plant 1/Storage Pad Area) was taken from a core sample from a depth of $8.5 \mathrm{~cm}$. 
The contamination in this area resulted mainly from uranium product spills. The second sam. plant). This sample had been subjected to treatment procedures based on gravimetric separation (6).

The basic components of the contaminated soils have been identified by scanning electron microscopy (SEM) and $x$-ray diffraction (XRD) as various clays and quartz. Tirese examinations also revealed that uranium inclusions were associated with the clay fraction of the soil, but a unique description of the phases was not provided (1). This paper describes the characterization of uranium-bearing soil fractions including for both treated and untreated soil. The objectives of this paper are to (a) describe the use of a combination of optical microscopy, SEM using backscattered electrons (BSE), and analytical electron microscopy (AEM) as a coherent methodology to provide representative characterization data on the uranium-bearing phases within the contaminated soil, and (b) to identify discrete uranium phases found in Fernald soil fractions.

\section{Experimental Procedure}

Sample SP4, provided in gram quantity, was taken from the core, while SP10, provided in milligram quantity, was isolated after soil processing. For each sample, it was essential that a representative sample be isolated for analysis: therefore, a combination of optical microscopy, SEM, and AEM was used.

Uranium-bearing phases were isolated by using micromanipulation techniques, assisted by a Zeiss polarizing light microscope and a ISI SS-40 SEM that was equipped with a Robinson BSE detector. Thin sections for transmission electron microscopy (TEM) analysis were produced with a Reichert-Jung Ultracut E ultramicrotome. The thin sections were collected on slotted 150-mesh-carbon-coated copper grids. AEM 
was performed using a JEOL 2000FXII TEM, operated at $200 \mathrm{kV}$. Compositional analysis was carried out using two Noran Instruments energy dispersive $\mathrm{x}$-ray (EDS) detectors (an ultra-thin window light element detector and high take-off angle beryllium window detector), and a Gatan 666 parallel electron energy loss spectrometer (EELS).

Phases were analyzed by using EDS, EELS, selected area electron diffraction (SAED), and convergent beam electron diffraction (CBED). Electron diffraction data from uranium-bearing phases was compared to XRD data from the literature to assist in identifications. Because of the small size of many of the phases present in the soils, microdiffraction and CBED were often used to obtain structural data. The camera lengths were determined by using a polycrystalline aluminum standard. Compositions were calculated by using experimentally determined $k$-factors from mineral thin film standards (7).

An important aspect of the overall analysis was the development of a technique to follow a unique particle through each step in the analysis procedure. The main focus of the techniques was on the use of ultramicrotomy in preparing TEM sections.

\section{Results and Discussion}

The results are presented in two parts: the first discusses the unique methods developed for preparing TEM thin sections and the second discusses the characterization of the uranium contamination in the soil.

Ultramicrotomy. TEM thin-sectioning of isolated small particulates by ultramicrotomy is well described in the literature $(8,9)$. Thin sections of soil constituents have been prepared using microtomy, but the technique has seen limited use in gross soil studies. Wada and Kakuto (10) have examined clays in soils by TEM, producing samples by embedding the soils in epoxy and then sectioning them. 
Ghabru et al. (11) have also carried out high-resolution studies of clay minerals by impregnating soils with Spurr's resin and then ultramicrotoming the samples. In studies where a representative sample of the bulk is required, it is necessary to show that one is observing the same regions in the SEM and in the TEM. This has usually been a difficult task to accomplish, as it requires producing an intact section along a precise direction and over a specific area. Comparison of SEM and TEM images allows greater confidence in determining whether uranium-bearing phases are not just peculiarities, but true representations of the major uranium-bearing phases in the soil.

Preparation of TEM Thin Sections. To provide a representative characterization of uranium phases distributed in soil, a relatively large number of unaltered particles must be examined. This was achieved by mounting particles for SEM and examining polished cross-sections with SEM/BSE. Because the objective was to use an embedding resin that would allow thin sectioning of a uranium-containing particle directly from the SEM mount, it was imperative to use a resin with optimum infiltration and sectioning properties. Particles were either mounted in inverted BEEM capsules (for small quantities) or in a suitable flat mold (for large quantities). A flat shallow mold has the advantage of being mountable in either the light microscope or the SEM. This allowed direct correlation between the optical microscopy images and the SEM images. Selected uranium-bearing particles were identified in the SEM on the basis of density, morphology, and compositional distinctions. Micrographs of regions containing uranium-bearing phases were taken and annotated, so that particles of interest could be examined in the polarizing optical microscope and used for TEM studies. Particles of interest in the flat molds were isolated for ultramicrotomy by scribbing the resin around the particle and gluing this piece onto a sectioning block stub. When the particles were closely spaced in the 
inverted BEEM capsules, it was possible to shape two regions on the block face for simultaneous thin sectioning.

Ultramicrotomy of soil particles is the most appropriate means of viewing the undisturbed spatial relationship of soil components. The difficulty in selecting and formulating an embedding resin for soil particles arises from the variety of soil components each with differing mechanical properties, and from the requirements for producing a good section. Mechanical tests performed on a variety of embedding resins have helped in understanding the relationship between resin properties and the interaction of forces involved in forming a thin section (12). The results of tensile and bending tests combined with evaluation of thin sections, support the requirements for a resin that has a high elastic modulus and low plasticity. These characteristics favor a cleavage mechanism of sectioning, whereas true sectioning would be favored by a softer more plastic resin.

Section quality can be substantially improved by selecting a resin that has good cohesion and matched hardness with the sample. Such a resin helps minimize sample heterogeneity resulting in a more uniform thin section. Sectioning of the brittle, impenetrable components in the soils, such as quartz and uranium oxide inclusions, can be optimized by determining the best microtome sectioning parameters, such as sectioning speed, cutting angle, and section thickness. Shattering of brittle phases is unavoidable, but good cohesion between particle and resin will usually hold some material at the interface, whereas poor cohesion would cause complete plucking out and redeposition of shattered pieces over the section's surface.

Because of the differences in resin properties and the large size distribution, heterogeneity, and anisotropy of the soil particles, it was necessary to evaluate several kinds of embedding media. The thermosetting epoxies commonly used in the 
preparation of TEM thin sections did not provide representative samples because of inadequate infiltration of the large particles and the clay fraction. An acrylic resin that is miscible in ethanol and eight times less viscous than the epoxy was used in a solvent replacement infiltration procedure. This procedure improved section quality considerably but did not provide intact regions of the more compact structures and did not have satisfactory polishing characteristics or beam stability.

The best improvement in infiltration was achieved with a water soluble melamine resin that was used to replace water in wetted soil particles. Frösch et al. (13) compared sections made of the polar melamine resin and a nonpolar epoxide resin; their results showed that the melamine resin produced much thinner and smoother (i.e. low surface relief), thin sections. A rough surface indicates that a large amount of plastic work has taken place prior to rupture. This entails a larger energy requirement in comparison to the smoother melamine section which undergoes less plastic flow. Therefore less energy is required to break the bonds and thin sections as thin as $<10 \mathrm{~nm}$ thick can be obtained with the melamine resin. The particles were prepared following a procedure similar to that used to prepare aquatic colloids (14).

When the melamine resin waas used the SEM results show an improvement in the polished surface and in the infiltration of large particles. Because the spatial relationship of uranium phases within the larger particles was well preserved, more uranium-containing areas could be isolated in a given field of view. The increased section quality made it possible to produce completely intact sections that are thinner than sections obtained with the epoxy and acrylic resins. Because of these improvements, the uranium phases identified in the TEM could be correlated with the corresponding areas in the SEM/BSE image.

In Figure 1, structures from the same particle can be seen in both the SEM and TEM 
micrographs. The slight discrepancy in particle morphology between the SEM and TEM images is due to the sectioning process, which may occur over a depth of $\sim 3 \mu \mathrm{m}$; however, the overall structure of the particles is preserved.

Characterization of Uranium Phases. Characterization of uranium-bearing phases involved the combination of optical microscopy, SEM, and AEM. Each of these techniques provided vital information which allowed, in many instances, complete characterization of the phases.

Optical Investigation of SP4. Soil sample SP4 was examined using an optical microscope, in an effort to correlate uranium phases with specific optical characteristics. The refractive indexes of uranium phases are characteristic for identification. Fluorite, zircon, and a few uranium oxides were identified, but the images were not clear because the uranium phases were probably too small or not well formed. Discrete uranium mineral phases can usually be identified in the optical microscope (5). The fact that such phases were not observed suggests weathering of the soil with subsequent redistribution of uranium into secondary minerals has not occurred in the sample SP4.

Soil Mineralogy. While the general mineralogy of the soil samples has been described by Lee and Marsh (1), we sought to identify the specific phases in the current samples which would allow us to determine the distribution of uranium within the clay fraction of the soils. TEM examination of the soils revealed two major components, quartz and clay. Quartz does not section well, so shattered particles of quartz were often found displaced from their original sites. In Figure 2, a quartz particle can be seen surrounded by clay particles. Clay mineral types in SP4 were identified as mica and chlorite by SAED, EDS composition data, and the clay morphology. However, specific clay minerals could not be positively identified with 
the method of analysis used. Unembedded clay minerals exposed to the TEM environment suffer water loss and subsequent collapse of the layers to around $10 \AA$. In addition, variation of focusing and angle of tilt have significant implications for imaging of clay lattice fringes (15). Lattice images were taken with an objective aperture that excluded all $h k l$ reflections except the basal $\{00 l\}$. The images of clay minerals displaying (001) lattice fringes were taken along with EDS composition data, to identify mineral types (Figure 3 ). The $\sim 10 \AA$ spacings were identified as coming from illite, whereas chlorite was identified by its composition and $\sim 15 \AA \mathrm{c}$-axis spacings. Electron diffraction data from these phases are presented in Table I. Other phases were found in SP4, including rutile, possibly maghemite (iron oxide), calcium phosphate, and zirconium silicate (possibly zircon which was identified by optical microscopy).

Identification of Uranium-Bearing Phases. AEM analysis showed that there were at least three major types of phases that contained uranium: a calcium phase, an iron oxide phase, a uranium oxide phase, and a uranium phosphate phase. Minor amount sof uranium were associated with clay based on the EDS detection capabilities. The following describes in detail the AEM analysis of uranium-bearing phases observed in the soil samples SP4 and SP10.

(a) Uranium in Fluorite. For sample SP4, calcium and uranium were detected together in a number of SEM analyses, which indicated that this phase was an important uranium-bearing phase (Figure 4) The calcium phase, though crystalline, consisted of many small crystallites and it was not possible to obtain single-crystal patterns by SAED; therefore, a convergent beam was used. SAED analysis produced a polycrystalline diffraction pattern which matched with fluorite (see Table II). MicroCBED, which was applied to obtain single-crystal patterns (Figure 4c), which was also consistent with cubic fluorite. Patterns of the $<111>$ and $<101>$ zone axes are shown. 
EDS analysis indicated the phase was calcium fluoride (see Table III). This analysis was confirmed using the higher spatial resolution of EELS (see Figure 5), which demonstrated that oxygen was not a major component of this phase. The broad carbon-K edge is the result of the amorphous carbon substrate's randomly oriented $\sigma^{*}$ bonding configurations (16). The minerals of the fluorite group can incorporate uranium into their structures, with oxygen being taken up to maintain electroneutrality. If uranium was contained within the calcium fluoride phase, it may well have been ordered within this structure, so forming a superlattice, however, no such structures were observed.

The calcium-to-uranium ratio in element weight percent for the fluorite phases was found to be around 7:2 (about one uranium atom for every 20 fluorite unit cells). The uranium concentration remained fairly constant with respect to calcium, except in one instancé (see Table IV). Large and small probes were placed at all regions over the calcium particles, suggesting that uranium is unlikely to be adsorbed on the surface of the particles but instead contained within the $\mathrm{CaF}_{2}$ structure. If uranium were only adsorbed one would expect the Ca:U ratio to vary with the probe size.

(b) Uranium in Iron Oxides. Amorphous uranium-bearing iron oxide phases were observed in many regions of the soil sample SP4. This type of uranium phase had a different morphology compared to that of the calcium phase. It consisted of small (100 nm diameter) particles which often appeared to be strung together into a much larger agglomerate. On occasions, both calcium and iron uranium phases were observed in close proximity (i.e., $<1-2 \mu \mathrm{m}$ separation). In Figure 6a, an SEM/BSE image of a uranium-containing particle is shown along with its complimentary TEM image (Figure 6b).

Silicon was also found during the EDS analysis of these phases but EELS was able to 
show that this silicon was actually not part of the iron uranium phase. Generally, a higher concentration of uranium was found in the iron uranium oxide phase than in the calcium fluoride phase. The uranium concentration varied considerably, from around 10 to $60 \mathrm{wt} \%$ (see Table V), suggesting that the uranium was adsorbed onto the surfaces of the iron oxide particles. Hsi and Langmuir have observed the $\mathrm{pH}$ dependent adsorption of uranyl [U(VI)] on various iron oxides (17). They found that adsorption was greatest for an amorphous iron oxyhydroxide and for goethite $(\alpha \mathrm{FeOOH})$ at $\mathrm{pH}>5$. Uranyl adsorption on synthetic and natural hematite was lower than the other iron oxides.

(c) Uranium Oxide Phases. Uranium oxide particles were found in both the processed soil from SP10 and, less frequently, in the core samples from SP4. The SAED pattern of uranium oxide phases found in SP4, located in the vicinity of the calcium fluoride phase described earlier, matched with fluorite $\left(\mathrm{UO}_{2+\mathrm{x}}\right) \cdot \mathrm{UO}_{2}$ has not been identified in nature because it is usually found in an oxidized nonstoichiometric state (18).

Figure 7 clearly shows the effect of the uranium phase separation based on density differences for sample SP10. Most of the contamination was in the form of large particles, and the AEM identified these phases as uranium oxide and uranium phosphate (indicated in the figure). Bulk uranium analysis showed that not all the uranium was isolated in this experiment (19), which may suggest that physical separation processes can only be used successfully with a limited number of phases. The SAED and CBED patterns matched closest with cubic nonstoichiometric fluorite $\mathrm{UO}_{2+\times}$ (see Figure 8a and Table.VI for electron diffraction data).

(d) Uranium Phosphate Phase. A uranium phosphate phase was found in one group of particles in SP4. Judging from the morphology, the phase was crystalline: 
however, SAED analysis failed to detect any signs of crystallinity. The uranium phosphate particles were elongated and micrographs appeared to display lattice fringes (Figure 9). There are a range of possible uranium phosphate phases, most of which are so electron beam sensitive that structural analysis is difficult to obtain.

In SP10, the second major phase found was also a uranium phosphate phase. In Figure 10, long, fibrous particles of the uranium phosphate phase can be observed. The uranium phosphate phase appeared to be connected to the uranium oxide, suggesting that the uranium phosphate was an alteration product. The SAED pattern produced was square and had spacings of $5.02 \AA$ and $6.88 \AA$ (see Figure 9). Other patterns were obtained, for which the spacings of the (001) plane were calculated to be -9-10 $\AA$. The phase was identified on the basis of these patterns as a tetragonal metaautunite uranyl phosphate hydrate $\left[\mathrm{M}^{2+}\left(\mathrm{UO}_{2}\right)_{2}\left(\mathrm{PO}_{4}\right)_{2} \cdot \mathrm{xH}_{2} \mathrm{O}\right]$. The most commonly obtained pattern was the square SAED pattern, which was taken along the $<001>$ zone axis of the uranium phosphate phase. The identification of the uranium-bearing phase by SAED has also indicated the uranium is in the uranyl state [U(VI)]. Autunites are well-known alteration products of uraninite (5). Alteration of uraninite to a nonstoichiometric oxidized phase can result in the eventual formation of three types of uranium phases: gummite (e.g. schoepite), autunites (uranium phosphates), and uranophanes (e.g. boltwoodite) (20). Uranium waste from the incinerator may have undergone accelerated weathering, which may account for these types of phases being observed in the vicinity of the plant. In SP4, where some uranium oxide particles were observed, there was no evidence of any alteration of the phase.

(e) Uranium in Clays. Clay minerals are known to have an affinity for uranyl species, and they take up uranium by adsorption either onto the surface of the clay or within interlayer sites $(21,22)$. The affinity for cation sorption depends on the clay 
mineralogy and the nature of the cation which compensates for the negative surface charge. At Fernald, bulk analysis of soil samples have suggested that uranium is associated with clay phases, based on gross studies of the large soil fraction. In the present study, a mica-group clay was found not to contain uranium, but a small amount of uranium ( $<1 \mathrm{wt} \%)$ was found to be associated, on occasions, with a chlorite-group clay. Chlorite alteration has been found to affect uranium redistribution at Koongarra, Australia (3). At times, a high concentration of uranium in the clay phases was observed, but this phase was later identified as a discrete uranium silicate phase (Figure 11).

(f) Uranium Silicate Phase. Crystalline uranium silicate phases were found in SP4, and the electron diffraction from this phase, which is displayed in Table VII, was consistent with soddyite $\left[\left(\mathrm{UO}_{2}\right)_{2}\left(\mathrm{SiO}_{4}\right) 2 \mathrm{H}_{2} \mathrm{O}\right]$, a uranyl silicate commonly found as an alteration product both in laboratory-reacted and field-weathered uraninite $(4,5)$. It has a high uranium to silicon ratio which distinguishes it from other uranium silicates (23). However, EDS analysis of the phase found in SP4 yielded a smaller than expected U:Si ratio, which was probably due to the difficulty in quantifying uranium accurately. The presence of this phase does suggest that some weathering of the uranium has occurred in the core soil sample SP4 that was not observable with optical microscope. The phase was found sandwiched between clay minerals (see Figure 11), which suggests that discrete uranium phases may be forming in the soil preferentially, rather than underging adsorption onto the clay minerals present.

Implications for Remediation Technolgies. The application of optical, SEM, and AEM provided a clearer picture of uranium contamination at Fernald. The evidence suggests that some of the weathering processes at Fernald have resulted in the alteration of the initial uranium-bearing phases, and that soluble uranium interacted only slightly with the clay phases in the soil substrate, based on the sensitivity of the 
EDS system (0.1 wt\% detection limit).

Effective removal of uranium from the Fernald soils will depend on detailed knowledge of the chemical and physical characteristics of the waste and its environment. The characterization methods described above, in combination with other methods under development (24), will allow remediation technology groups to find a more direct and efficient way of removing the contamination. These techniques are intended to be transferred for implementation at contaminated sites operated by the DOE and private sector. For example, plutonium contamination at Johnston Atoll (25), Hanford (26), and Maxey flats (27), are areas where similar techniques could be applied.

Without information describing the nature of the uranium contamination, remediation technologies must operate by trial and error, which may result in repetitive processing and an even greater volume of contamination than was initially present.

\section{Conclusions}

The core sample SP4 contained a larger number of uranium-containing phases than the procurred sample SP10. The greater diversity in the SP4 sample may reflect the difficulty in concentrating uranium in soils by the physical separation processes; however, because only a limited number of soils have been examined at present, such a conclusion is mere speculation. Further studies of core and processed samples from the same site are underway to investigate the effectiveness of separation processes by characterizing the uranium-bearing phases isolated from the soil.

Selected soil samples from SP4 and SP10 have been examined by optical microscopy combined with SEM and AEM. With these methods of analysis, we were able to isolate and characterize discrete uranium-bearing phases in the Fernald soils. With 
optical microscopy, no large uranium-bearing secondary minerals were observed. With SEM, however, clumps of uranium-rich regions were identified. Upon further examination with AEM, these regions were found to be composites of finely dispersed phases, which were both crystalline and amorphous. Little uranium was associated with the clay substrate itself. The types of uranium-bearing phases observed at Fernald such as the amorphous uranium iron oxides phases and the altered uraninite, are similar in many cases to those found in other environments. While it is necessary to show that these results apply to larger soil samples, the utility of using multiple techniques for uranium phase identification and characterization has been demonstrated (28).

\section{Acknowledgements}

Isolation of uranium by density differences was achieved by D.Chaiko (Argonne National Laboratory). Optical investigations were aided by R.C.Ewing (University of New Mexico).

\section{Literature Cited}

(1) Lee, S. Y.; Marsh,J. D. ORNL/TM-11980, Oak Ridge National Laboratory, 1992

(2) Edis, R. Mat. Res. Soc. Symp. Proc., 1991, 212, 727

(3) Edghill, R.Radiochimica Acta., 1991, 52/53, 381

(4) Wronkiewicz, D. J.; Bates, J. K.; Gerding, T. J.; Veleckis, E.; Tani, B. S. J.Nuc.Mat., $1992,192,107$

(5) Finch. R. J.; Ewing, R. C. J.Nuc.Mat., 1992, 190, 133

(6) Chaiko, D. Uranium in Soils ID meeting, Cincinnati, OH, October 17, 1991

(7) Cliff, G.; Lorimer, G. W. J.Microscopy, 1975, 103, 203

(8) Hayat, M. A. Principles and Techniques of Electron Microscopy: Biological Applications:3rd ed., CRC Press Inc., Boca Raton, FL (1989)

(9) Kay. D. Techniques for Electron Microscopy; Blackwell Press, Oxford, 1965 
(10) Wada, K; Kakuto, W. Clays and Clay Minerals, 1989, 37,263

(11) Ghabru, S. K.; Mermut, A. R.; St. Arnaud, R. J.; Soil. Sci.Soc.Am.J., 1990, 54 , 281

(12) Acetarin, J-D.; Carlemalm, E.; Kellenberger, E.; Villiger, W. J.Electron.Microsc.Techniq., 1987, 6 , 63

(13) Frösch, D.; Westphal, C.; Bachhuber, K. Ultramicrocopy, 1985, 17 , 141

(14) Perret, D.; Leppard, G. G.; Müller, M.; Belzile, N.; de Vitre, R.; Buffle, J. Water Research, 1991, 25,1333

(15) Veblen, D. R.; Guthrie, G. D.; Livi, K. J. T.; Reynolds, R. C. Clays and Clay Minerals, 1990, 38,1

(16) Katrinak, K. A.; Rez. P.; Buseck, P. R. Environ.Sci.Technol., 1992, 26, 1967

(17) Hsi, C-K. D; Langmuir, D. Geochimica et Cosmochimica Acta, 1985, 49 , 1931

(18) Janecek, J.; Ewing, R. C. J.Nuc.Mat., 1991, 185,66

(19) Chaiko,D. personal communication, Argonne National Laboratory (1992)

(20) Johnson, L. H. ; Shoesmith, D. W. Spent Fuel, in Radioactive Wasteforms for the Future ; Lutze, W, Ewing, R. C., Eds.; Elsevier, 1988 p.665.

(21) Staunton, S.; Clay, P. G.; Rees, L. V. C. Radiochimica.Acta., 1990, 49 , 147

(22) Ames,L.L.; McGarrah,J.E.; Walker,B.A. Clays and Clay Minerals, 1983, 31 , 343

(23) Stohl,F.V.; Smith,D.K. American Mineralogist, 1981, 66, 610

(24) Cunnane, J. C. ; Lee, S. Y. ; Perry, D. L. ; Tidwell,V. C., Gill, V.; MickelsonM. Waste Management'93, March 2-5, Tuscon, AZ.

(25) Bramlitt, E. T. Health Physics, 1988, 55,451

(26) Sheppard, J. C. ; Campbell, M. J.; Kittrick, J. A. ; Hardt, T. L. Environ.Sci.Technol., $1979,13,680$

(27) Cleveland, J .M. ; Rees, T. F. Science, 1981, 212, 1506

(28) Work supported by the US Department of Energy, Office of Technology Development, as part of the Uranium in Soils Integrated Demonstration Program, under W-31-109-ENG-38. 

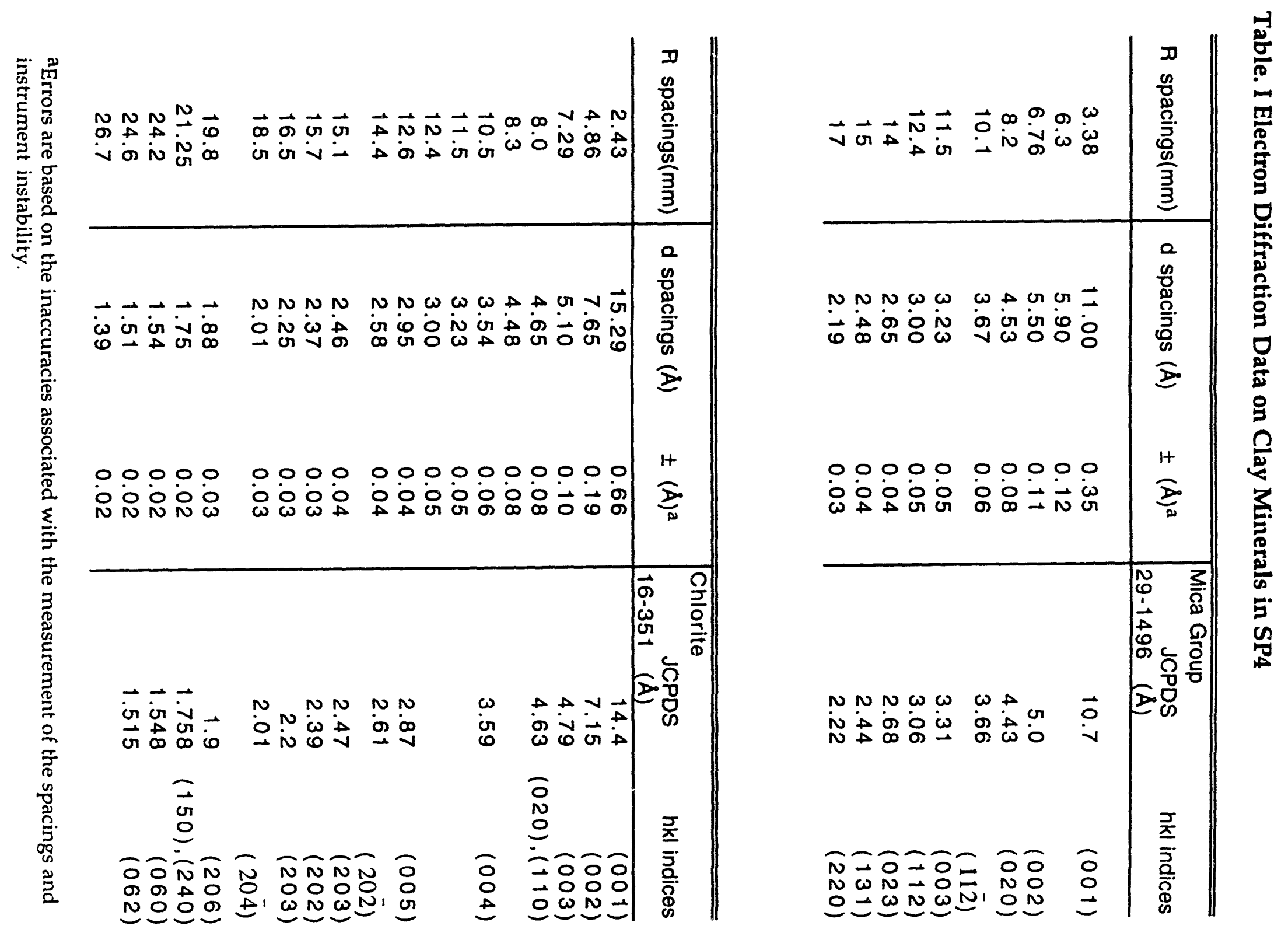
Table.II Electron Diffraction Data from Calcium Fluoride Phase

\begin{tabular}{c|cc|cr}
\hline \hline R spacings $(\mathrm{mm})$ & $\mathrm{d}$ spacings $(\AA)$ & $\pm(\AA)^{\mathrm{a}}$ & $\begin{array}{c}\text { Calcium Fluoride } \\
\text { JCPDS 4-864 }\end{array}$ & hkl indicies \\
\hline 11.8 & 3.16 & 0.05 & 3.15 & $(111)$ \\
13.4 & 2.77 & 0.04 & & \\
19.0 & 1.96 & 0.03 & 1.93 & $(220)$ \\
19.3 & 1.93 & 0.03 & 1.93 & \\
22.3 & 1.67 & 0.02 & 1.65 & $(311)$ \\
24.0 & 1.55 & 0.02 & & \\
26.9 & 1.38 & 0.02 & 1.37 & $(400)$
\end{tabular}

Table.III EDS Composition Data on Calcium Fluoride phase

\begin{tabular}{l|ll}
\hline \hline El & Atom \% & El wt\% \\
\hline Ca & 42.3 & 52.5 \\
F & $55.7^{b}$ & $32.8^{b}$ \\
U & 2.0 & 14.7
\end{tabular}

$b_{\text {Fluorine }} \mathrm{k}$-factors are inaccurate, because like oxygen $\mathrm{K}$, high absorbance of the low energy $\mathrm{F}$ $\mathrm{K} x$-ray in the phase results in this element being underestimated.

Table.IV Calcium to Uranium

Element wt\% ratio in Fluorite phase

\begin{tabular}{l|l}
\hline \hline $\mathrm{Ca}$ & $\mathrm{U}$ \\
\hline 3.3 & 1.0 \\
3.05 & 1.0 \\
3.6 & 1.0 \\
3.7 & 1.0 \\
3.45 & 1.0 \\
16 & 1.0
\end{tabular}

Table V. EDS Analysis of a number of different Iron Uranium

Oxide Particles found in SP4.

\begin{tabular}{ll}
\hline \hline El wt\% \\
\hline \hline $\mathrm{U}$ & $\mathrm{Fe}$ \\
\hline 30.6 & 69.4 \\
20.1 & 79.9 \\
33.2 & 66.8 \\
67.9 & 32.1 \\
33.0 & 67.0 \\
87.4 & 12.6 \\
41.2 & 58.8
\end{tabular}




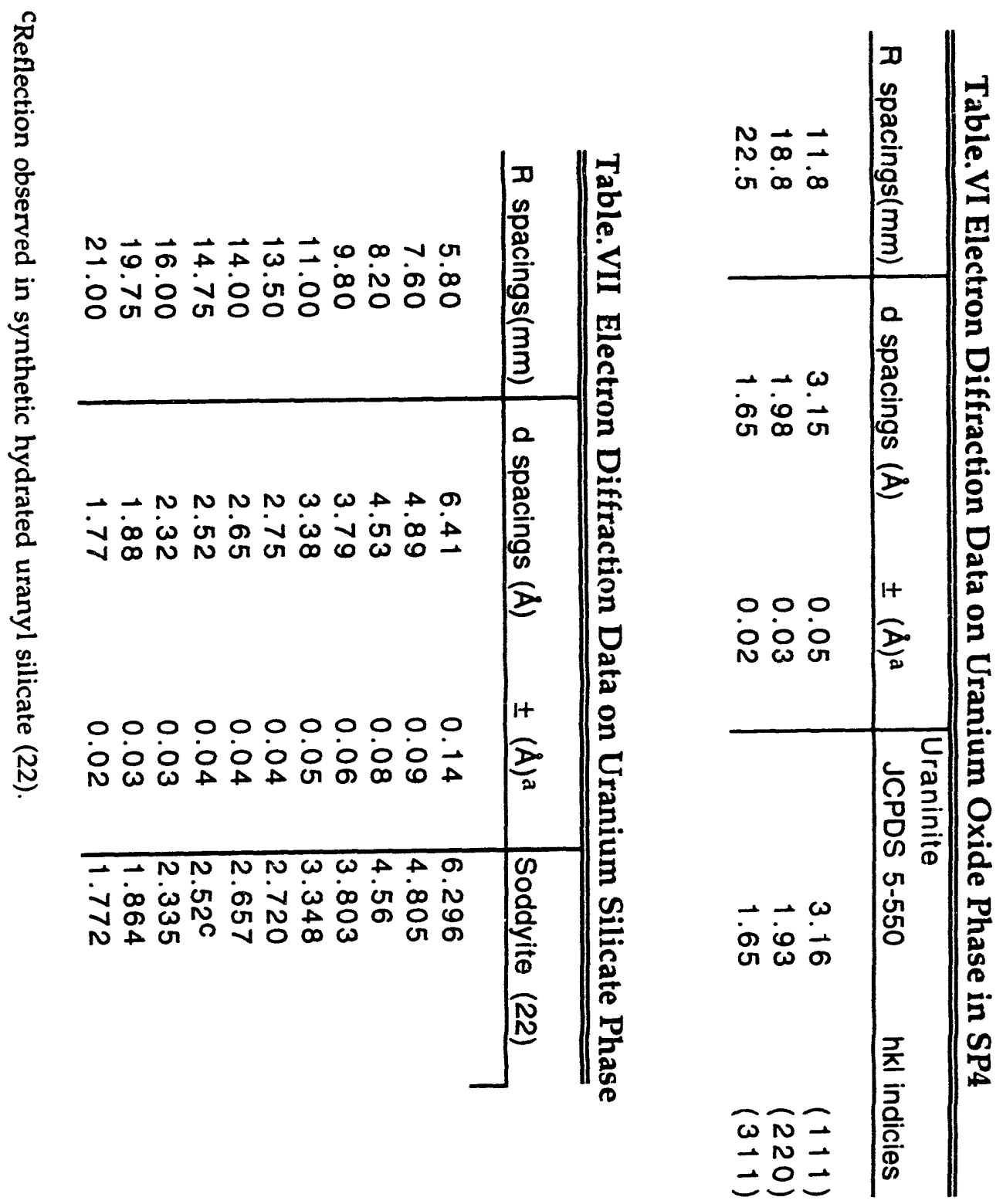


Figure 1. (a) SEM/BSE micrographs showing an oval particle, which can also be seen in the (b) TEM image. The uranium-contaminated regions can be identifed by the white BSE contrast. The particles are similar in shape because the SEM mount has been sectioned nearly parallel to the plane of the paper.
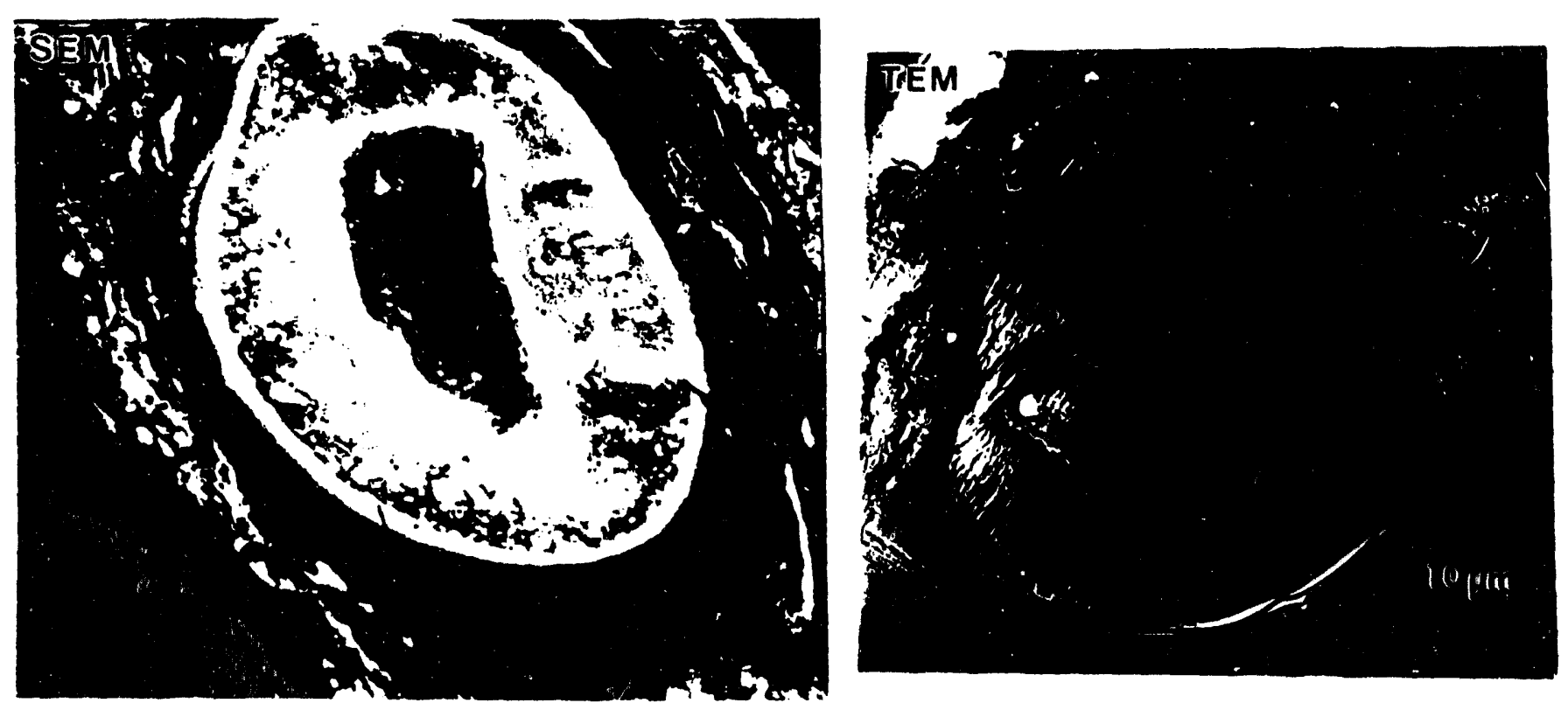


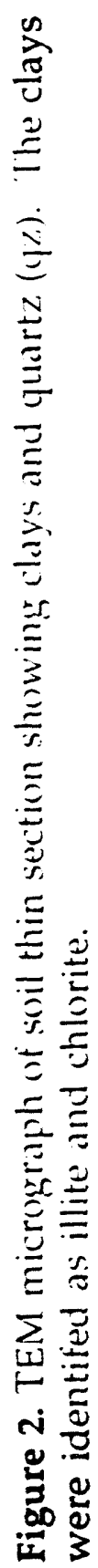

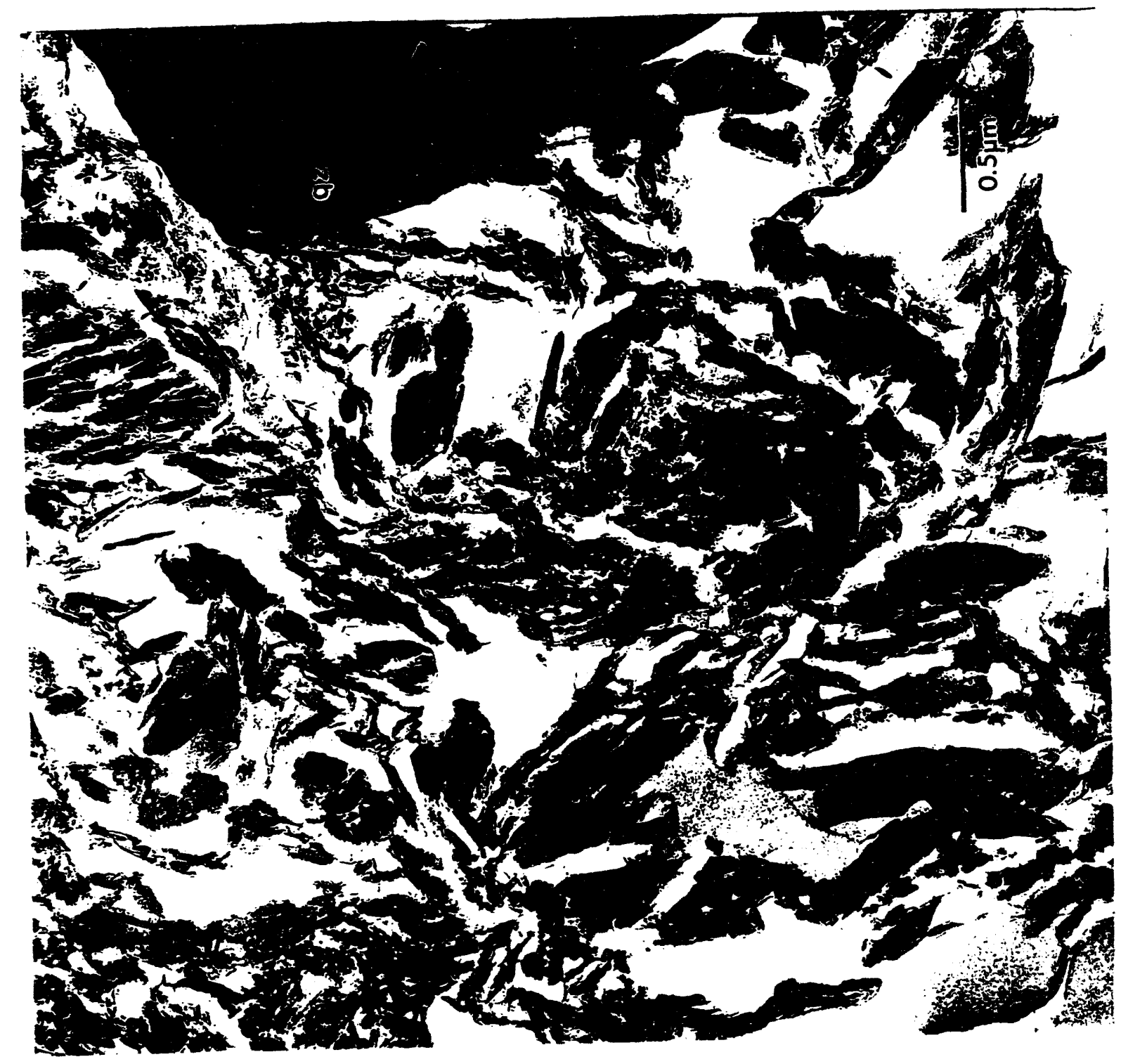


Figure 3. Lattice images of (a) illite and (b) chlorite (vermiculite) with c-axis spacings of $\sim 1.0 \mathrm{~nm}$ and $\sim 1.5 \mathrm{~nm}$ respectively.
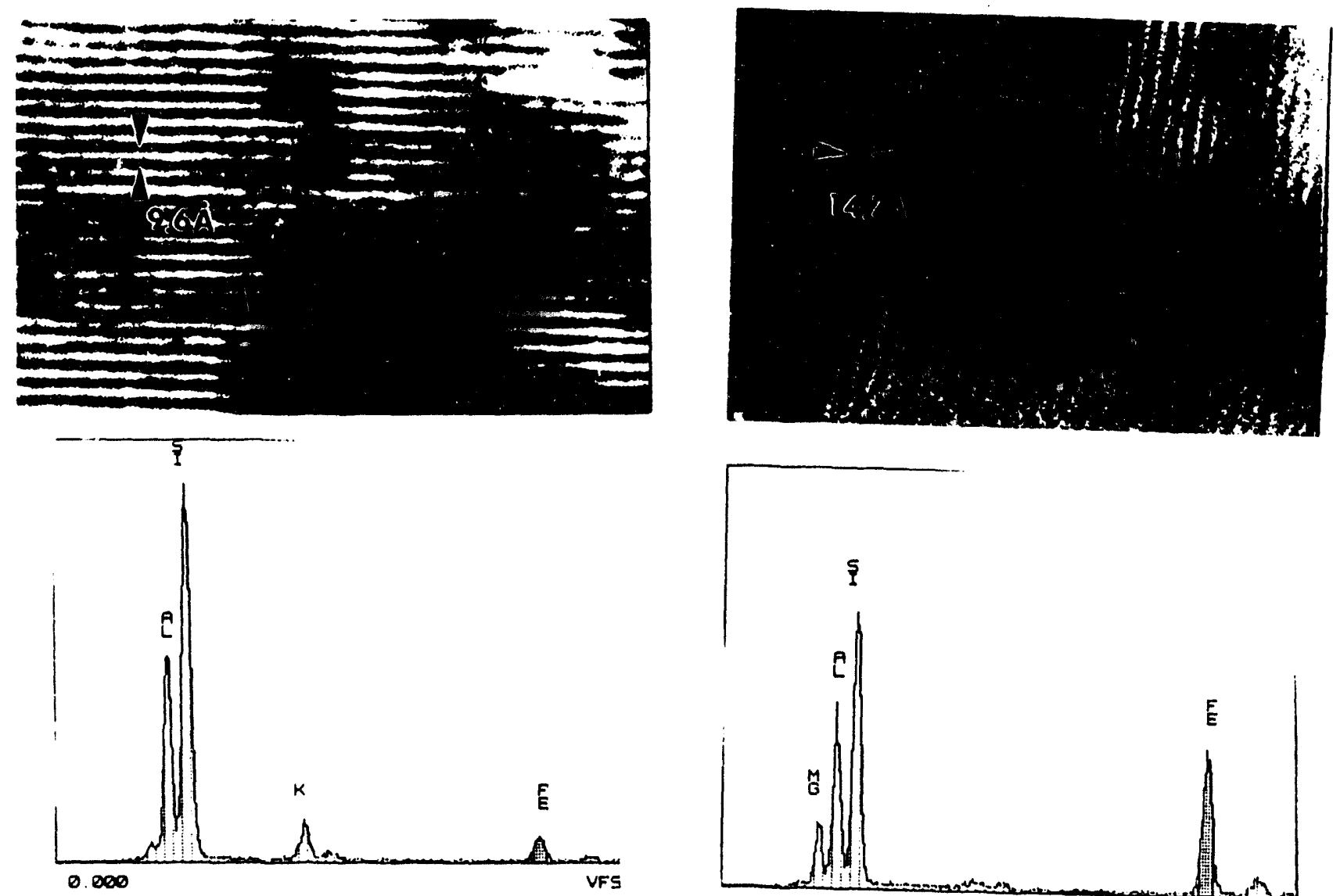

Compositions

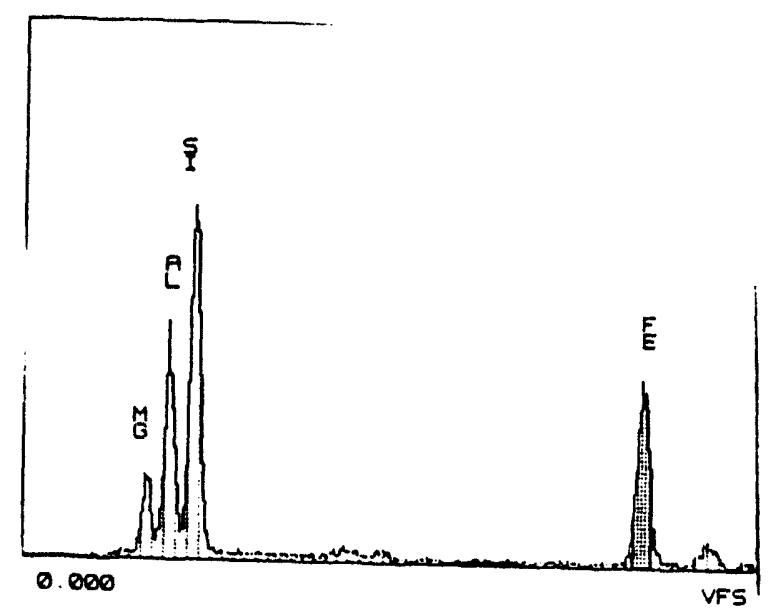

Ideal: $\quad \mathrm{K}\left(\mathrm{Fe}_{0.5}, \mathrm{Al}_{1.5}\right)\left(\mathrm{Si}_{3} \mathrm{Al}\right) \mathrm{O}_{10}(\mathrm{OH})_{2}$

$(\mathrm{Mg}, \mathrm{Fe}, \mathrm{Al})_{6}\left(\mathrm{Si}_{3.3} \mathrm{Al}_{0.7}\right) \mathrm{O}_{10}(\mathrm{OH})_{8}$

EDS analysis: $\quad \mathrm{K}_{0.75} \mathrm{Fe}_{0.3} \mathrm{Al}_{1.4}\left(\mathrm{Si}_{3} \mathrm{Al}\right) \mathrm{O}_{\mathbf{x}}$

$\left(\mathrm{Mg}_{1.65} \mathrm{Fe}_{1.15} \mathrm{Al}_{2.8}\right)\left(\mathrm{Si}_{3.3} \mathrm{Al}_{0.7}\right) \mathrm{O}_{\mathrm{x}}$ 
Figure 4. Bright field micrograph of a uranium-bearing phases (a) which were identified as fluorite by (b) SAED, micro-CBED.
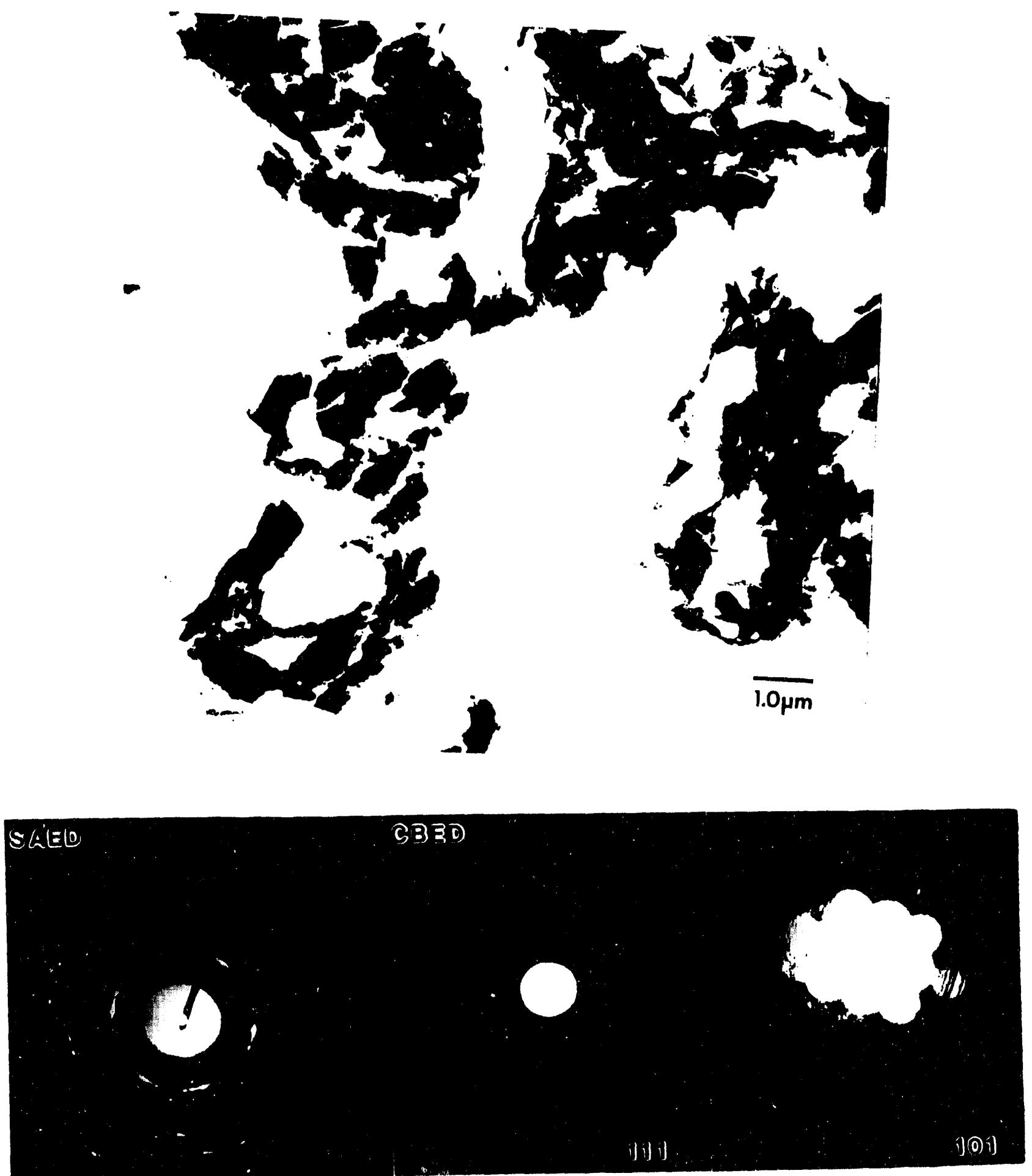
Figure 5. The EELS recorded $\mathrm{Ca}-\mathrm{L}_{2,3}$ edges, $\mathrm{F}-\mathrm{K}$ edge and the $\mathrm{U}-\mathrm{M}_{4,5}$ edges were used along with EDS to determine composition of the fluorite phase as $\mathrm{CaF}_{2}$.
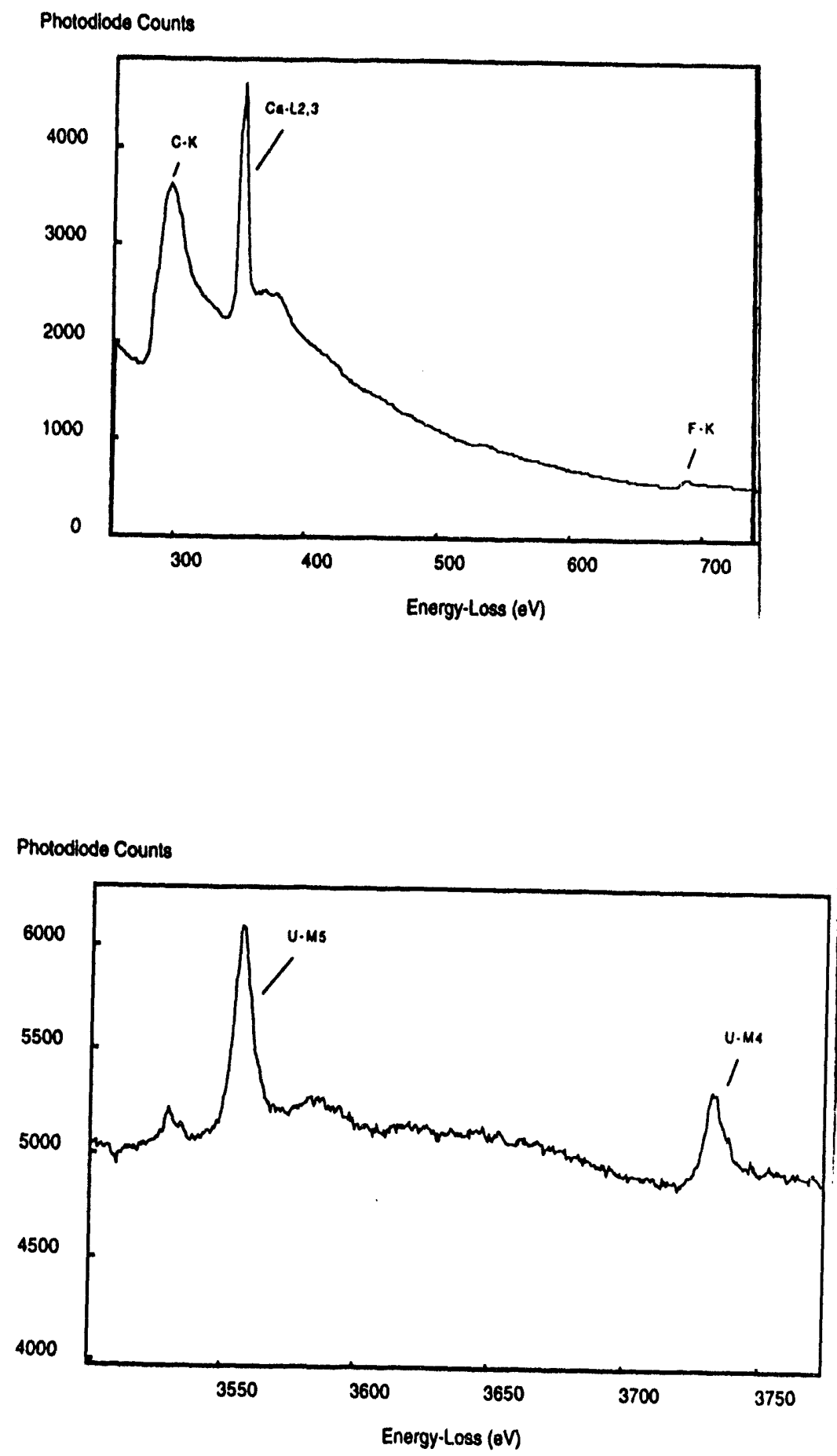
Figure 6. A major uranium-bearing phase found in $\mathrm{SP}_{4}$ was an amorphous iron oxide phase. A particle containing uranium was found during SEM analysis (a) was characterized in the (b) TEM and shown to coniain clumps of uranium-rich iron oxide particles. The higher magnification micrographs (c) show the arrangement of the colloidal sized iron phases and clay which can only be detected with TEM (the arrows point to the uranium-bearing regions). EDS compositional analysis is shown in (d).
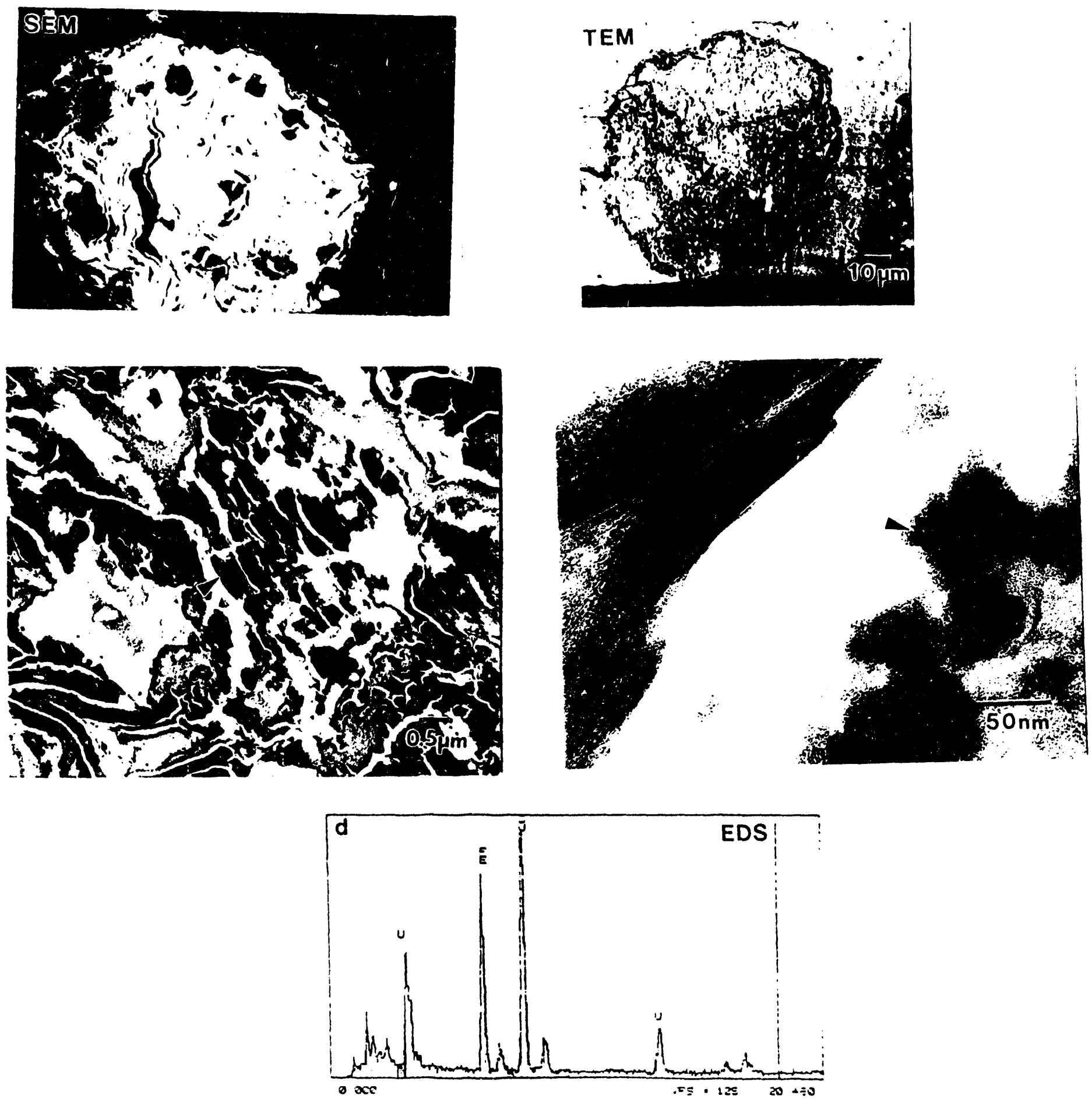
Figure 7. A density separation of uranium contamination in SP10 isolated two major phases; a uranium oxide and uranium phosphate. The darker clumps were identified as uranium oxide (i) and attached to these were uranium phosphate (ii) crystallites.

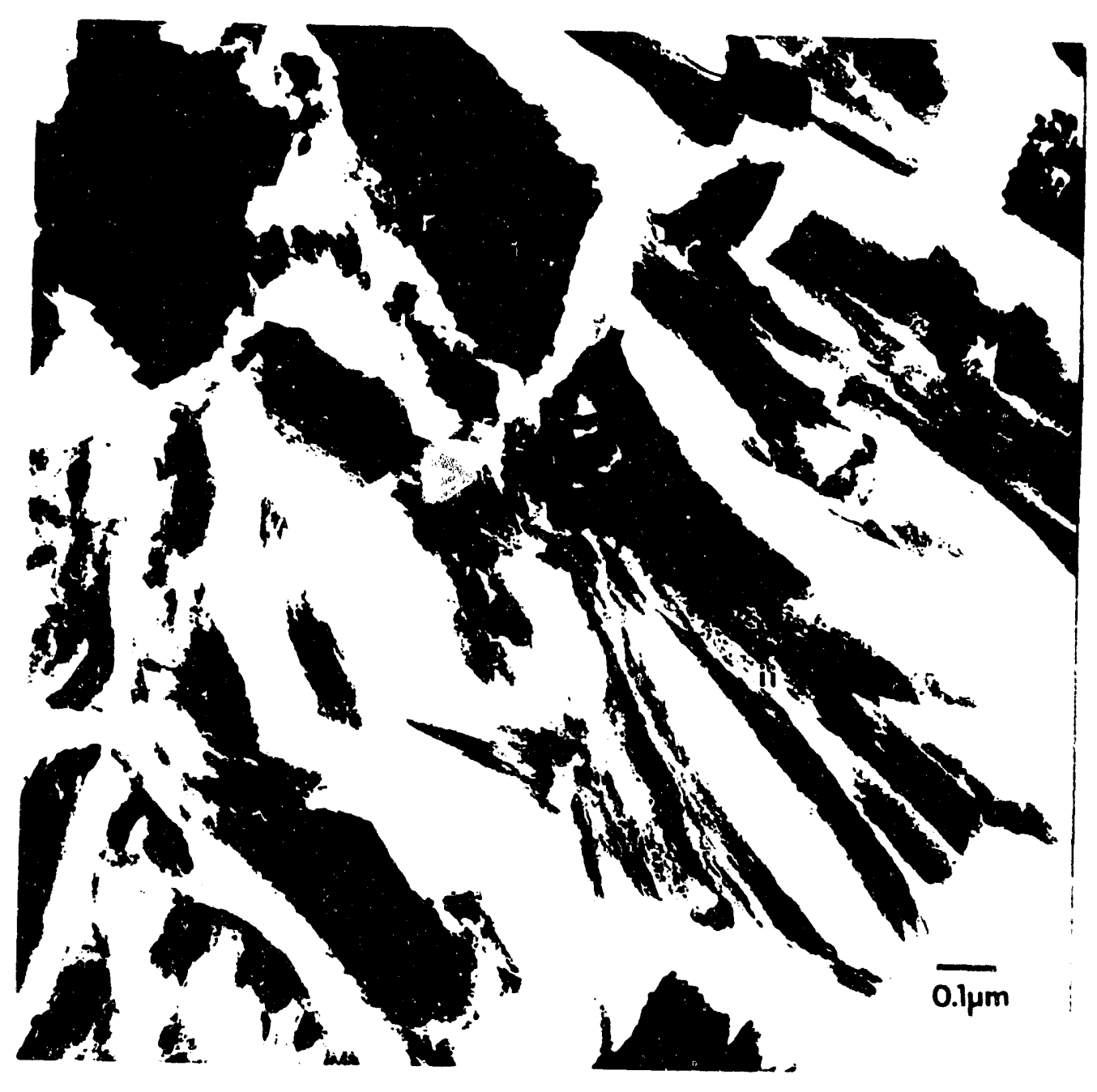


Figure 8. SAED pattern (a) of a uranium oxide particle taken down the $<\overline{1} 10>$ major pole and a CBED pattern (b) of the $<001>$ zone axis.

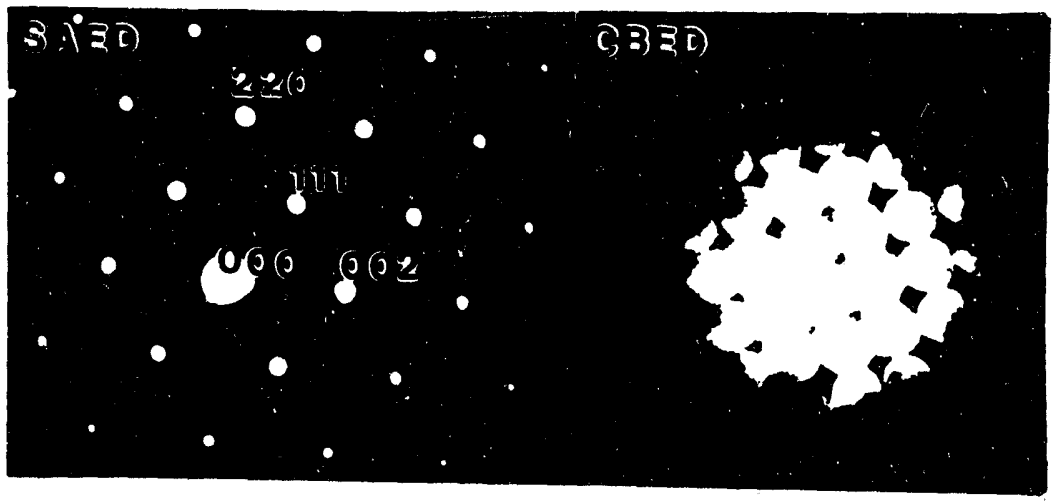


Figure 9. Uranium phosphate phase found in the core sample SP4.

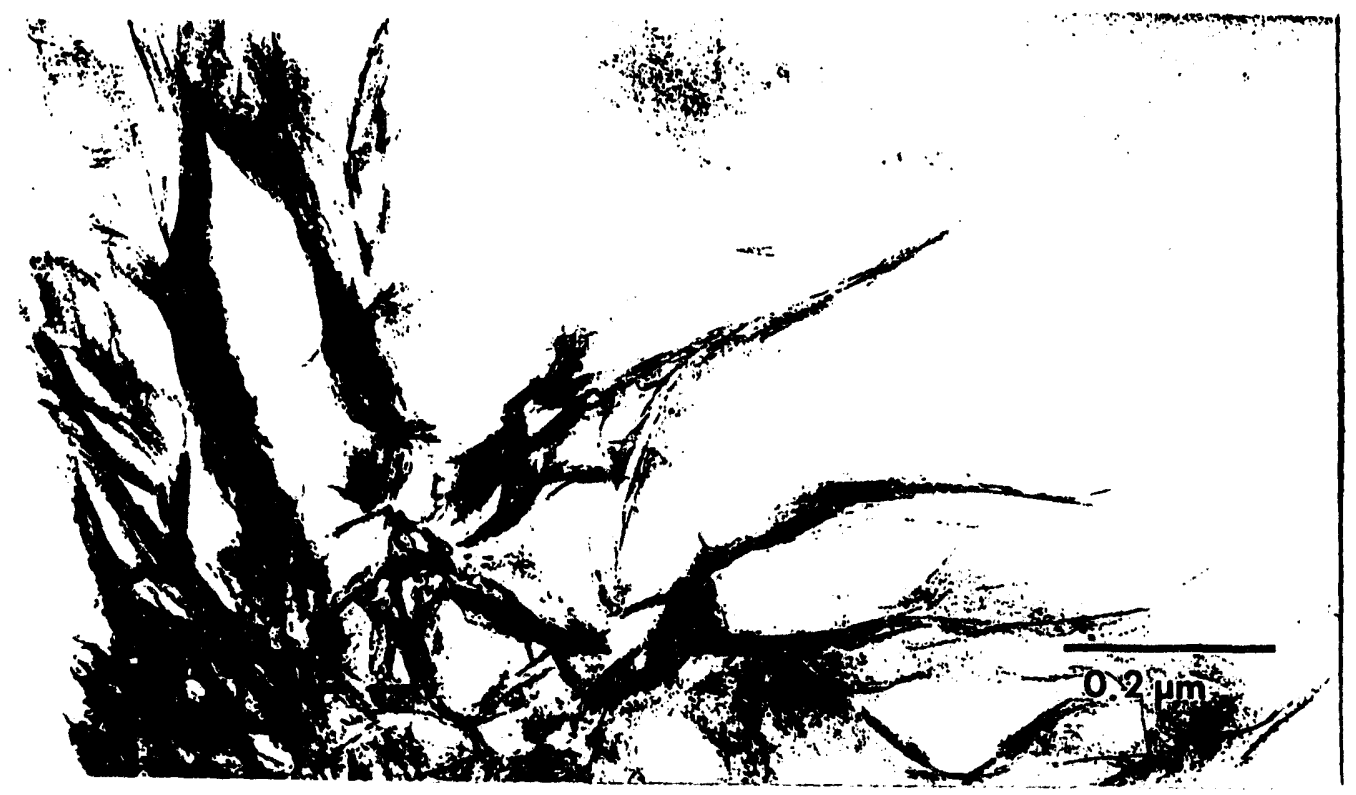


Figure 10. AEM determined the phosphate phase to be a tetragonal autunite, uranyl phosphate hydrate
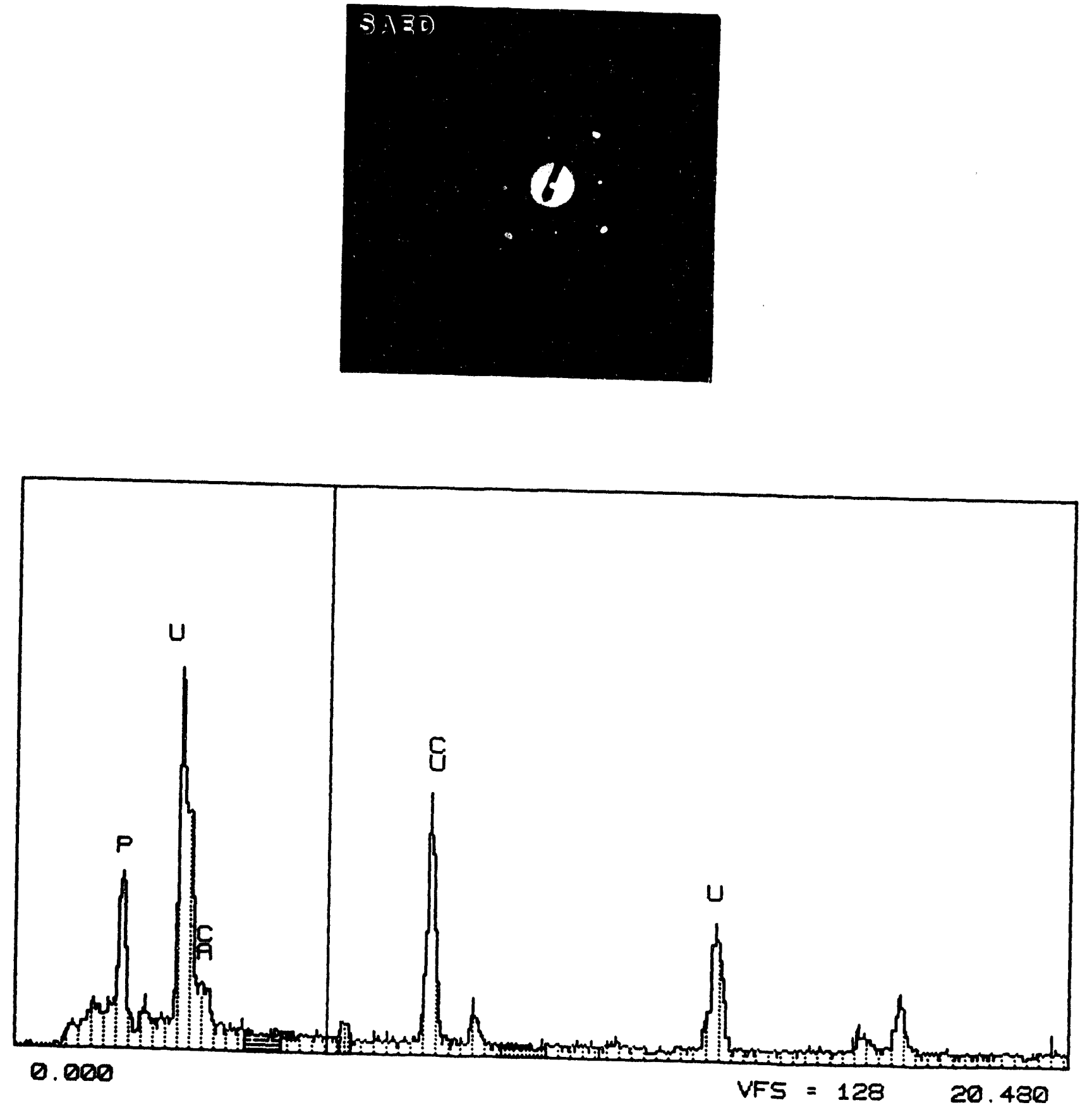
Figure 11. Within the clay phases a uranium-rich silicate phase was found (a) and identified as the uranyl silicate, soddyite $\left[\left(\mathrm{UO}_{2}\right)_{2} \mathrm{SiO}_{2} 2 \mathrm{H}_{2} \mathrm{O}\right]$ by electron diffraction (see Table VII) and EDS compositional analysis (b).

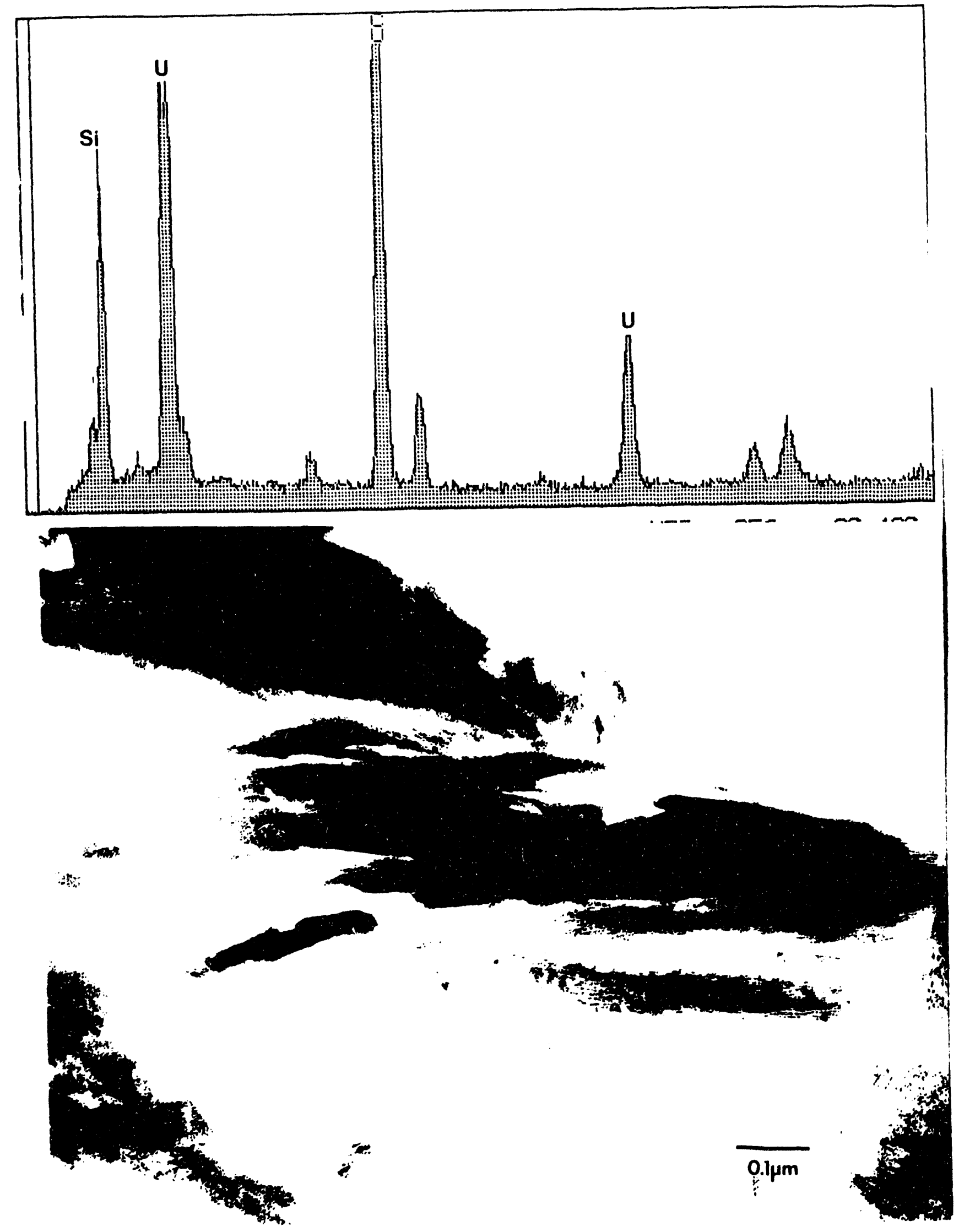



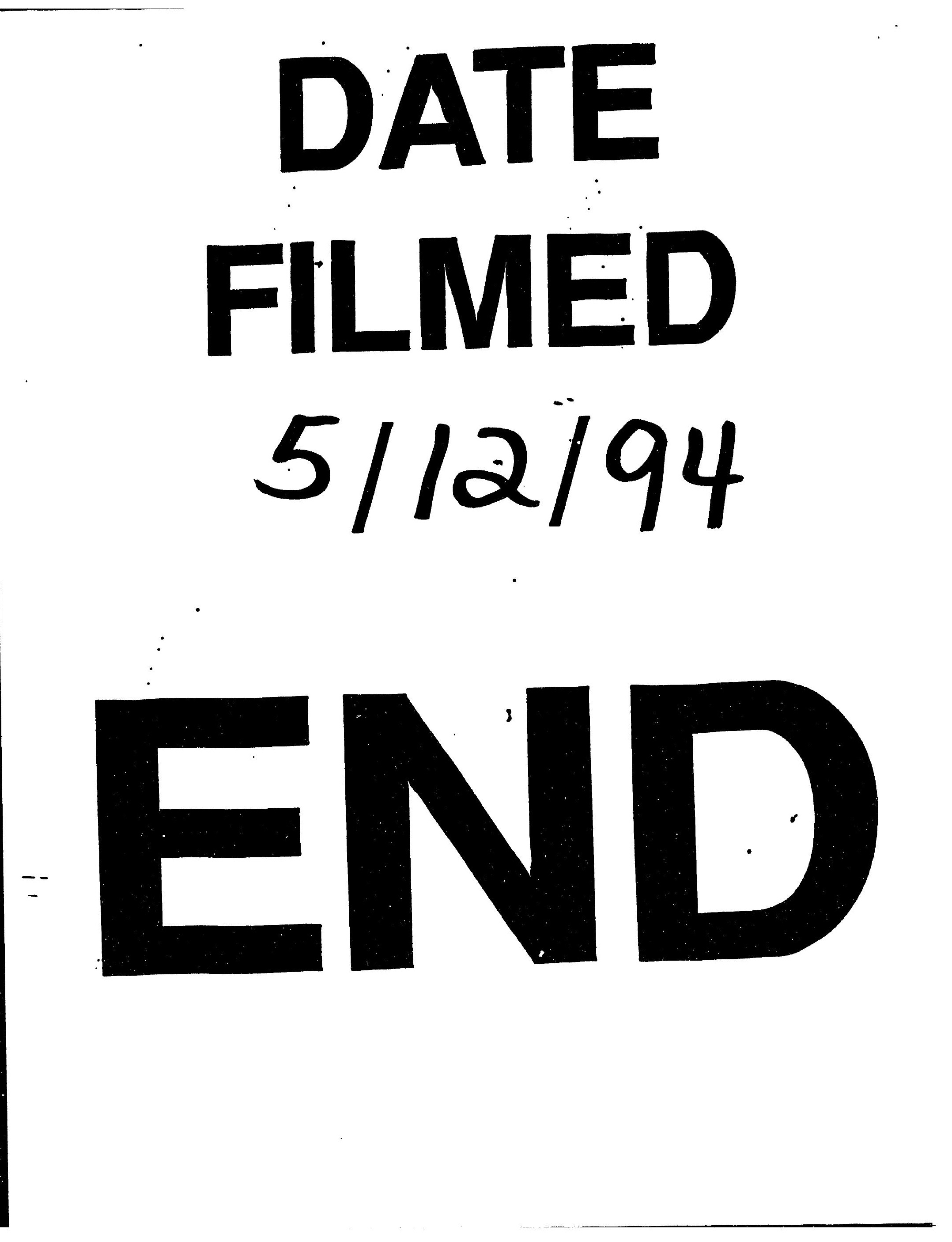


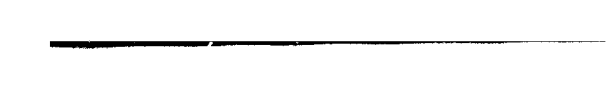

